\title{
IL-6/STAT3 Signaling Contributes to Sorafenib Resistance in Hepatocellular Carcinoma Through Targeting Cancer Stem Cells [Corrigendum]
}

Li Y, Chen G, Han Z, Cheng H, Qiao L, Li Y. Onco Targets Ther. 2020;13:9721-9730.
The authors apologize for this error and advise it does not affect the results of the paper.

The authors have advised due to an error at the time of figure assembly, Figure 4 on page 9728 is incorrect. The correct Figure 4 is shown below.

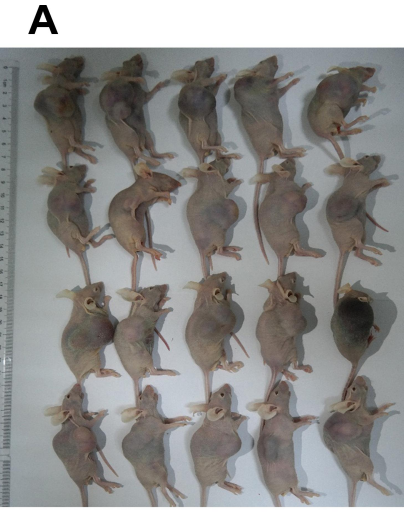

B

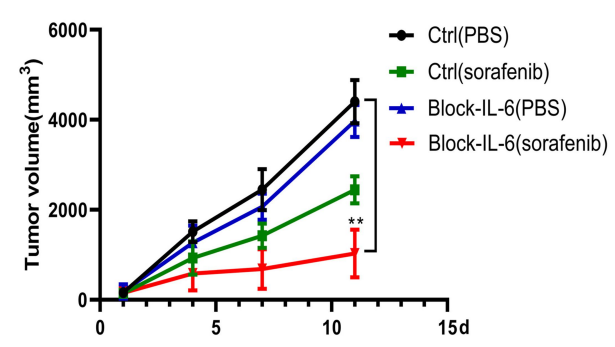

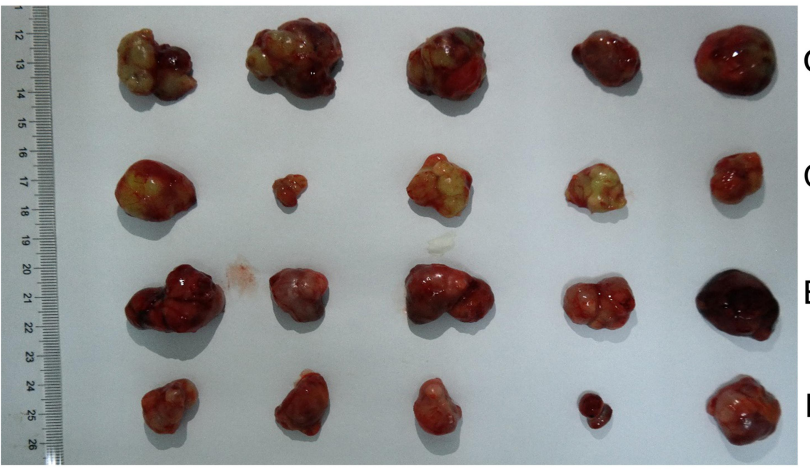

Ctrl(PBS)

Ctrl(Sorafenib)

Block-IL-6(PBS)

Block-IL-6(Sorafenib)
C

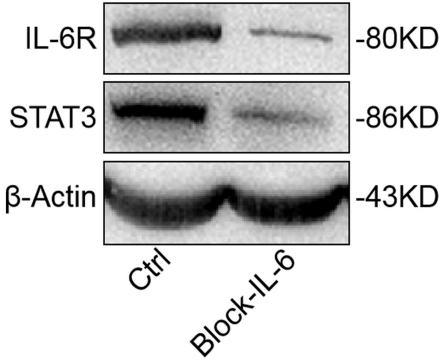

D

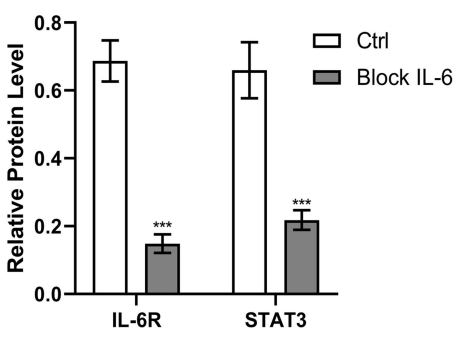

Figure 4 Continued. 
E

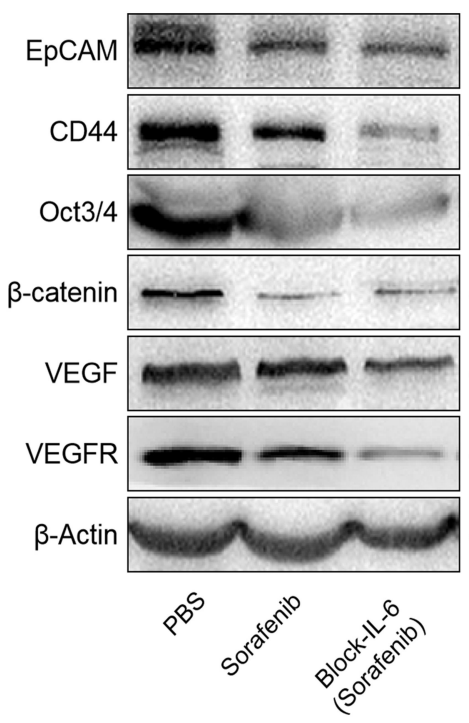

$\mathbf{F}$

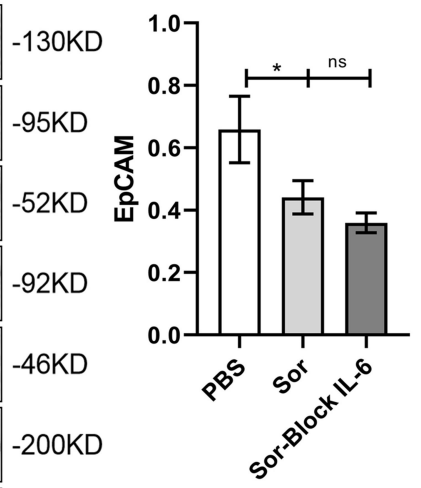

$-43 K D$

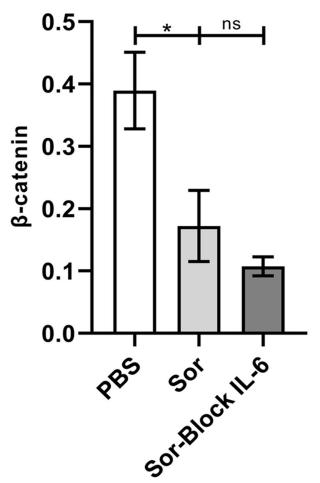

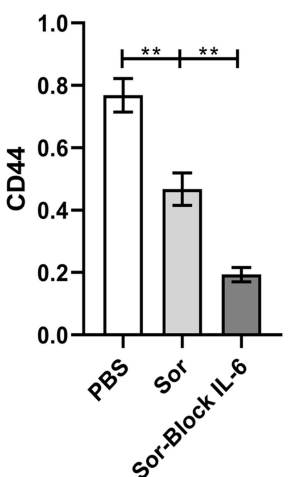
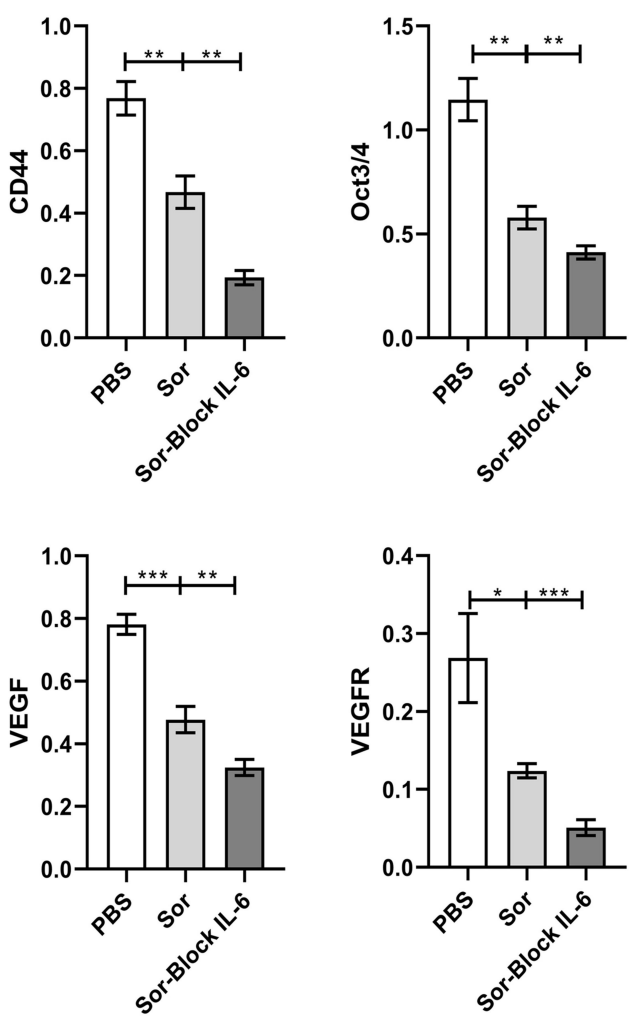

Figure 4 Establishment of subcutaneous xenografts in nude mice using resistant LCSCs, which block the IL-6/STAT3 signaling pathway. (A) Tumor images of all subcutaneous xenografts in nude mice. Each indicated treatment group included 5 mouse tumors. (B) Growth curves of xenograft tumors from day I to day II in various treatment groups. (C, D) Analysis of IL-6R and STAT3 protein expression in xenograft tumors to confirm that the IL-6/STAT3 signaling pathway was blocked. (E, F) The LCSC markers (EPCAM and CD44), stemness markers (Oct3/4 and $\beta$-catenin) and angiogenic factors (VEGF and VEGFR) were assessed by WB (Sor-Block-IL-6): subcutaneous xenograft tumors in nude mice were established using resistant LCSCs, which blocked IL-6 signaling, treated with sorafenib, $100 \mathrm{mg} / \mathrm{kg} / \mathrm{d}$; sor: subcutaneous xenograft tumors in nude mice were established using resistant LCSCs, in which IL-6 signaling is NOT blocked, and sorafenib as the treatment, $100 \mathrm{mg} / \mathrm{kg} / \mathrm{d}$; PBS: subcutaneous xenograft tumors were established in nude mice using resistant LCSCs, in which IL-6 signaling is blocked, and PBS as the treatment (ns $P>0.05, * P<0.05, * * P<0.01, * * * P<0.005$ ).

\section{Publish your work in this journal}

OncoTargets and Therapy is an international, peer-reviewed, open access journal focusing on the pathological basis of all cancers, potential targets for therapy and treatment protocols employed to improve the management of cancer patients. The journal also focuses on the impact of management programs and new therapeutic agents and protocols on patient perspectives such as quality of life, adherence and satisfaction. The manuscript management system is completely online and includes a very quick and fair peer-review system, which is all easy to use. Visit http://www.dovepress.com/ testimonials.php to read real quotes from published authors. 